\title{
Regular consumption of pulses for 8 weeks reduces metabolic syndrome risk factors in overweight and obese adults
}

\author{
R. C. Mollard, B. L. Luhovyy, S. Panahi, M. Nunez, A. Hanley and G. H. Anderson* \\ Department of Nutritional Sciences, Faculty of Medicine, University of Toronto, 150 College Street, Toronto, ON, \\ Canada M5S 3E2 \\ (Submitted 31 August 2011 - Accepted 13 September 2011)
}

\section{Abstract}

Pulses are low in energy density, supporting their inclusion in the diet for the management of risk factors of the metabolic syndrome (MetSyn). The aim of the present study was to describe the effects of frequent consumption (five cups/week over 8 weeks) of pulses (yellow peas, chickpeas, navy beans and lentils), compared with counselling to reduce energy intake by $2093 \mathrm{~kJ} / \mathrm{d}$ (500 kcal/d), on risk factors of the MetSyn in two groups (nineteen and twenty-one subjects, respectively) of overweight or obese $\left(\mathrm{mean} \mathrm{BMI} 32 \cdot 8 \mathrm{~kg} / \mathrm{m}^{2}\right.$ ) adults. Body weight, waist circumference, blood pressure, fasting blood parameters and $24 \mathrm{~h}$ food intakes were measured at weeks 1 , 4 and 8. Blood glucose, insulin, C-peptide, glucagon-like peptide-1 (GLP-1) and ghrelin were measured after a $75 \mathrm{~g}$ oral glucose load at weeks 1 and 8. At week 8, both groups reported reductions in energy intake, waist circumference, systolic blood pressure, glycosylated $\mathrm{Hb}(\mathrm{HbA1c})$ and glucose AUC and homeostasis model of insulin resistance (HOMA-IR) following the glucose load $(P<0 \cdot 05)$. However, HDL, fasting C-peptide and insulin AUC responses were dependent on diet $(P<0.05)$. HDL and C-peptide increased by 4.5 and $12.3 \%$, respectively, in the pulse group, but decreased by 0.8 and $7.6 \%$, respectively, in the energy-restricted group. Insulin AUC decreased in both females and males on the energy-restricted diet by 24.2 and $4.8 \%$, respectively, but on the pulse diet it decreased by $13.9 \%$ in females and increased by $27.3 \%$ in males $(P<0.05)$. In conclusion, frequent consumption of pulses in an ad libitum diet reduced risk factors of the MetSyn and these effects were equivalent, and in some instances stronger, than counselling for dietary energy reduction.

Key words: Whole pulses: Metabolic syndrome: Blood glucose: Cholesterol

The metabolic syndrome (MetSyn) is a cluster of risk factors (characteristics) of chronic disease, including abdominal obesity, dyslipidaemia, hypertension and hyperglycaemia ${ }^{(1)}$. Individuals with the MetSyn are at a higher risk of developing type 2 diabetes and $\mathrm{CVD}^{(2-5)}$. One of the main treatments for the MetSyn is lifestyle modification (diet and exercise) aimed at weight loss ${ }^{(6)}$. Energy restriction is the cornerstone of most weight-loss strategies ${ }^{(7)}$; however, evidence suggests that the majority of individuals who lose weight regain it during subsequent months or years ${ }^{(8)}$. Thus, it is important to identify foods that can be easily incorporated into the diet and spontaneously lead to the attainment and maintenance of a healthy body weight and improved metabolic control.

Bean consumption has been associated with lower body weight, waist circumference, risk of overweight or obesity and systolic blood pressure in epidemiological studies ${ }^{(9)}$. Whether the association of bean consumption (and possibly of other pulses) with healthier body weight and risk factors of the MetSyn is due to physiological effects of pulses or simply an indicator of a healthy lifestyle is uncertain.

Pulses are the edible seeds of legumes or pod-bearing plants and include beans, chickpeas, yellow peas and lentils. Because they are high in protein and dietary fibre (soluble and insoluble) and also low in energy density, pulses may be suggested as a functional food in diets for the reduction and control of the MetSyn. Short-term studies have shown that pulse consumption results in lower blood glucose $\mathrm{s}^{(10-12)}$ and insulin responses, as well as improved insulin sensitivity ${ }^{(11)}$ and suppressed appetite $^{(12)}$ compared with white bread.

Two recent meta-analyses that investigated the effects of pulses in randomised controlled trials concluded that there are long-term benefits of pulse consumption (two to five cups per week for 3 to 12 weeks) on risk factors of the MetSyn $^{(13,14)}$. The first found that pulse consumption lowered total cholesterol (TC) and LDL, while HDL, TAG and body weight were not changed ${ }^{(13)}$. The second concluded that

Abbreviations: CRP, C-reactive protein; GLP-1, glucagon-like peptide-1; HbA1c, glycosylated Hb; HOMA-IR, homeostasis model assessment of insulin resistance; MetSyn, metabolic syndrome; TC, total cholesterol.

*Corresponding author: Dr G. H. Anderson, fax +1 416978 5882, email harvey.anderson@utoronto.ca 
pulse consumption alone, in low-glycaemic index (GI) or high-fibre diets, improved markers of glycaemic control ${ }^{(14)}$.

To our knowledge, there are no reports comparing the effects of frequent pulse consumption as a dietary intervention in an ad libitum diet with dietary counselling to reduce energy intake on risk factors of the MetSyn in overweight and obese adults. Thus, the objective of the present study was to compare the effects of adding five cups of pulses per week to an ad libitum diet compared with dietary counselling to reduce energy intake by $2093 \mathrm{~kJ} / \mathrm{d}(500 \mathrm{kcal} / \mathrm{d})$ on risk factors of the MetSyn in overweight and obese adults over 8 weeks. We hypothesised that regular pulse consumption incorporated into an ad libitum diet would spontaneously reduce risk factors of the MetSyn and this effect would be similar to that of counselling to reduce energy intake.

\section{Methods \\ Participants}

Participants were recruited through local newspaper advertisements and posted flyers. Men and women aged 35-55 years with a BMI of $27-39.9 \mathrm{~kg} / \mathrm{m}^{2}$ were eligible to participate. Exclusion criteria included smoking, use of medications that could interfere with the study outcomes (i.e. statins, metformin, angiotensin-converting-enzyme (ACE) inhibitors, $\beta$-blockers) or any major surgery or medical conditions within 6 months before the start of the study. Also, those with gastrointestinal, liver or kidney disease and women who were pregnant or lactating were not eligible. Potential participants who met the eligibility criteria were scheduled for a screening interview. At this appointment, participants provided written informed consent and then body weight (kg) (Tanita BWB-800, Tanita Corporation of America Inc.) and height $(\mathrm{m})$ (Health-O-Meter, Continental Scale Corp.) were measured. They also completed self-administered baseline questionnaires determining health status, food habits and physical activity participation. These questionnaires were completed to determine eligibility and establish a baseline of the participants' food habits and physical activity participation so that deviations over the study period away from their normal lifestyle patterns could be identified. During the study, participants were asked to continue their daily routines, habits and follow their normal lifestyle patterns except for the requested dietary changes of the study. Eligible participants interested in participating signed an ethics consent form and were randomised into one of two diet groups (pulse or energy-restricted) using a randomisation chart. Participants in the two dietary groups were not matched for any parameters and menstrual cycle was not controlled for. The University of Toronto Health Sciences Research Ethics Board approved all aspects of the study protocol.

Classification of the MetSyn was according to the National Cholesterol Education Program Adult Treatment Panel III working definition (following new blood glucose criteria), which has been used to assess prevalence in various populations $^{(15-19)}$. Participants were considered to have the MetSyn if they had three of the following: (1) abdominal obesity: waist circumference $\geq 102 \mathrm{~cm}$ in men and $\geq 88 \mathrm{~cm}$ in women; (2) high TAG $\geq 1.69 \mathrm{mmol} / 1$; (3) low HDL: $<1.0 \mathrm{mmol} / 1$ in men and $<1.3 \mathrm{mmol} / 1$ in women; (4) high blood pressure: $\geq 130 / 85 \mathrm{mmHg}$; (5) high fasting glucose: $\geq 5.6 \mathrm{mmol} / 1$. Determination of the number of participants who had the MetSyn was done at the end of study.

\section{Dietary design}

Pulse diet. Pulses included lentils (Nupak), chickpeas (Nupak), yellow split peas (Nupak) and navy beans (Ferma). Participants were provided with five cups of pulses per week (on average $896 \mathrm{~g} /$ week) incorporated into servings of $754-1382 \mathrm{~kJ}(180-330 \mathrm{kcal})$ formulated and prepared in our kitchen (Table 1). A variety of pulses were provided based on Canada's Food Guide recommendation to include meat alternatives such as beans, lentils and tofu more often and this included lentils, chickpeas, yellow peas and navy beans. Pulses provided about $70 \%$ of the energy in the dishes. At the beginning of the study (week 1), a registered dietitian reviewed the study protocol with each participant, instructed participants on how to fill out a pulse log to record compliance and incorporate the pulses into their habitual diet. The pulse log included a record of the date and time of day and type of pulse consumed, other foods consumed during the pulse meal and gastrointestinal discomfort. Immediately following consumption of the pulse dishes, participants were asked to fill out specific information (ID, date and time) on a sticker attached to each container and return the clean empty containers with the stickers at the time of the next study session. Participants were provided with one salad, one soup and three side dishes per week and could choose to pick up the pulse dishes at the University of Toronto or have them delivered weekly. They were asked either in person when the pulse dishes were picked up or by phone following delivery if they liked the pulse dishes and if they had experienced gastrointestinal discomfort. At weeks 4 and 8, the dietitian met with the participants to review their pulse log.

Energy-restricted diet. A dietitian individualised the energy-restricted diet based on the participants' $24 \mathrm{~h}$ food recall. Dietitians provided dietary guidance to achieve recommended macronutrient ranges (45-65\% energy from carbohydrate, 20-35\% energy from fat, $10-35 \%$ energy from protein) and reduce energy intake by $2093 \mathrm{~kJ} / \mathrm{d}$ $(500 \mathrm{kcal} / \mathrm{d})$ through decreasing fat, sugar and alcohol intake, increasing fruit and vegetable intake and by portion control. Dietitians used measuring cups and spoons, as well as Canada's Food Guide as teaching tools. Participants received a copy of Canada's Food Guide, instructions on how to reduce their energy intake (based on $24 \mathrm{~h}$ food recall and speaking to the dietitian) and a measuring cup. At week 4 , the dietitian assessed the diet using a $24 \mathrm{~h}$ food recall, provided feedback and further instruction.

\section{Session protocol}

Participants attended three sessions (weeks 1, 4 and 8) in the research centre. Each subject arrived between 08.00 and 10.00 hours, but at the same time for each session after fasting 
Table 1. Pulse dish nutrient information*

\begin{tabular}{|c|c|c|c|c|c|c|}
\hline \multirow[b]{2}{*}{ Dishes } & \multicolumn{2}{|c|}{ Energy } & \multirow[b]{2}{*}{ Total carbohydrate $(\mathrm{g})$} & \multirow[b]{2}{*}{ Protein $(\mathrm{g})$} & \multirow[b]{2}{*}{ Fat $(\mathrm{g})$} & \multirow[b]{2}{*}{ Fibre $(\mathrm{g})$} \\
\hline & $\mathrm{kJ}$ & kcal & & & & \\
\hline Lentil salad & 754 & 180 & 28 & 12 & 3.5 & 14 \\
\hline Yellow pea and pepper salad & 837 & 200 & 37 & 13 & 1 & 14 \\
\hline Chickpea and pepper salad & 1130 & 270 & 40 & 12 & 9 & 11 \\
\hline Bean and sage salad & 1047 & 250 & 40 & 15 & 3.5 & 15 \\
\hline Lentil, potato and spinach soup & 862 & 206 & 40 & 14 & 6 & 15 \\
\hline Yellow pea soup & 1130 & 270 & 49 & 16 & 1.5 & 18 \\
\hline Creamy chickpea and rosemary soup & 1130 & 270 & 39 & 11 & 9 & 11 \\
\hline Mediterranean bean soup & 1172 & 280 & 47 & 15 & 3.5 & 15 \\
\hline Mexican lentils & 795 & 190 & 31 & 12 & 3 & 13 \\
\hline Cincinnati lentils & 963 & 230 & 44 & 14 & 2 & 16 \\
\hline Vegetarian lentils & 837 & 200 & 29 & 12 & 6 & 13 \\
\hline Savoury yellow peas & 1382 & 330 & 61 & 16 & 3 & 18 \\
\hline Yellow peas with basil & 1047 & 250 & 37 & 13 & 6 & 15 \\
\hline Yellow peas with garlic & 963 & 230 & 32 & 13 & 6 & 14 \\
\hline Peruvian chickpeas & 1256 & 300 & 46 & 13 & 9 & 13 \\
\hline Southern chickpeas & 879 & 210 & 37 & 12 & 4 & 11 \\
\hline Moroccan chickpeas & 1130 & 270 & 44 & 12 & 7 & 12 \\
\hline Navy beans & 754 & 180 & 28 & 12 & 3.5 & 14 \\
\hline Fiesta chilli & 1298 & 310 & 57 & 17 & 1.5 & 17 \\
\hline Tuscan beans & 1089 & 260 & 43 & 15 & 3.5 & 15 \\
\hline
\end{tabular}

*Each dish contained one cup of pulses.

for $12 \mathrm{~h}$. Only water was allowed until $1 \mathrm{~h}$ before blood collection. Participants filled out questionnaires including Sleep Habits and Stress Factors Questionnaire and a Food Intake and Activity Questionnaire. These questionnaires were completed to determine changes over the preceding $24 \mathrm{~h}$ that could have disturbed their present state (increased stress), compliance to the fasting protocol and deviations from usual patterns. If there were any issues identified, participants were rescheduled. Body weight, waist circumference (flexible steel tape; Rosscraft Innovations Inc.) and blood pressure (Intelli Sense; OMRON Healthcare Inc.) were recorded. Waist circumference $(\mathrm{cm})$ was measured at the part of the trunk located midway between the lower costal margin (bottom of lower rib) and the iliac crest (top of pelvic bone) while the person was standing. The tape was fit snugly around the subject's waist, without compressing any underlying soft tissues. The circumference was measured at the end of a normal expiration. Two measurements were taken and the average was used for analysis. Participants were asked to relax for $5 \mathrm{~min}$ before two blood pressure measurements. If there was a difference $>5 \mathrm{mmHg}$ in either systolic or diastolic blood pressure, a third measurement was done. The average was used for analysis.

At weeks 1, 4 and 8, fasting blood samples were taken by a registered nurse and analysed for glucose, insulin, TC, HDL, TAG, C-reactive protein (CRP), C-peptide and glycosylated $\mathrm{Hb}$ (HbA1c). At weeks 1 and 8, samples were also obtained for the measurement of fasting food intake-regulating hormones (adiponectin, leptin, glucagon-like peptide-1 (GLP-1) and ghrelin). Blood glucose, insulin, GLP-1 and ghrelin responses to a $75 \mathrm{~g}$ oral glucose load $(300 \mathrm{ml})$ (Glucodex $\AA$; Rougier Inc.) were determined over a $2 \mathrm{~h}$ period. After insertion of an intravenous catheter in the antecubital vein a fasting blood sample was obtained. The participants were given 5 min to consume the glucose drink and blood was collected at 10 , 20, 30, 60, 90 and $120 \mathrm{~min}$. Blood glucose and insulin were measured in all samples, while GLP-1 and ghrelin were measured at baseline and at 30, 60, 90 and $120 \mathrm{~min}$. Following blood collection, participants met with the dietitian to review the pulse $\log$ and/or to complete a $24 \mathrm{~h}$ food recall. Food intake recall data was collected from all participants and entered into The Food Processor SQL (version 10.3.0 program; ESHA Research) for energy and nutrient (carbohydrate, protein and fat) analysis.

Validated methods were used for all biochemical and hormonal analyses. Blood glucose, insulin, C-peptide, CRP, HbA1c, TC, HDL and TAG were analysed by the Mt. Sinai Hospital Clinical Biochemistry Hormone Assay Laboratory. Blood glucose was measured by the enzymic hexokinase method (Roche Diagnostics). Insulin and C-peptide were measured by electrochemiluminescence immunoassay (Roche Diagnostics), CRP was measured by particle enhanced immunoturbidimetric assay (Roche Diagnostics), TC and TAG were measured by enzymic colorimetric (Roche Diagnostics) and HDL was determined by homogeneous enzymic colorimetric test (Roche Diagnostics). LDL was calculated using the Friedewald equation by the following equation: $\mathrm{TC}-(\mathrm{HDL}+\mathrm{TAG} / 2 \cdot 2)$. HbA1c determination was based on the turbidimetric inhibition immunoassay (TINIA) for haemolysed whole blood. ELISA were used to measure leptin (Diagnostic System Laboratories), adiponectin (Millipore Corp.), active GLP-1 (Linco Research) and ghrelin (Millipore Corp.). All ELISA were conducted within our laboratory. Samples were run in duplicate and if the difference between duplicates was more than $10 \%$ for biochemical and hormonal analyses (or 15\% for ELISA, as recommended by the manufacturer), the samples 
were reanalysed. For all the assays, quality controls (QC) were used and an assay was only considered acceptable when all QC values fell within the calculated QC range. The information on accuracy and precision was provided by manufacturers. For instance, the reported accuracy for the GLP-1 ELISA (Millipore) is $86.9( \pm 5 \cdot 2) \%$, precision: $7 \cdot 4( \pm 1 \cdot 1) \%$ (intra-assay), and 8.0 ( \pm 4.8$) \%$ (inter-assay) (This information cited according to the following source: http://www.millipore.com/catalogue/item/ eglp-35k\#). For the ghrelin active ELISA, the accuracy is 94.7-94.8\%, inter-assay precision $7.5-12.9 \%$ and intra-assay precision $0.9-7.5 \%$; for the glucose enzymic (hexokinase) in vitro test on Roche automated clinical chemistry analysers, the repeatability (within-run precision) is $0 \cdot 8-1 \cdot 1 \%$, and intermediate precision (total precision/between-run precision/ between-day precision) is $1.7-1.9 \%$, for the insulin electrochemiluminescence immunoassay, the repeatability is $1.5-2.0 \%$, and intermediate precision is $2 \cdot 1-2 \cdot 8 \%$ when analysed on Elecsys 2010 or Cobas e 411 analysers.

\section{Statistical analysis}

A repeated-measures ANOVA using a PROC MIXED model was used to test for the effects of time and time $\times$ diet interaction. Tukey-Kramer post hoc tests were used to determine differences among weeks when there was a main effect of time. When there was an influence of sex on the response to treatment over time, it was included in the model. Independent $t$ tests were used to determine whether groups were significantly different at baseline. Statistical analysis was conducted using SAS (version 9.1; SAS Institute Inc.) and significance was concluded with $P<0 \cdot 05$.

Power analysis $(\alpha=0.05$; power $=0.8)$ indicated that the given sample size was sufficient to detect a clinically important range of 10-15\% difference between two groups (as well as an interaction with sex) for major markers of the MetSyn: waist circumference, fasting blood glucose and HbA1C, TC, HDL and postprandial glucose AUC.

\section{Results}

\section{Participants}

Of those screened, forty-seven participants met the eligibility requirements, of whom three declined to participate, citing lack of time as the main reason. A total of forty-four individuals began the study and two individuals dropped out during the study due to lack of time and one because they disliked the pulses. Also, one subject was removed from the study because the oral glucose tolerance test resulted in nausea. So, forty participants completed the 8-week study.

Of the forty participants that completed the study, seven had high fasting blood glucose $(\geq 5.6 \mathrm{mmol} / \mathrm{l})$, four had high fasting insulin $(>150 \mathrm{pmol} / \mathrm{L})$, twenty had high TC $(\geq 5.1 \mathrm{mmol} / \mathrm{l})$, twenty had high LDL $(\geq 3.3 \mathrm{mmol} / \mathrm{l})$, twentytwo had low HDL $(<1.0 \mathrm{mmol} / 1$ in men and $<1.3 \mathrm{mmol} / \mathrm{l}$ in women) and thirteen had high TAG $(\geq 1.69 \mathrm{mmol} / \mathrm{l})$ at the start of the study. Also, ten participants were classified as having the MetSyn (quantified at the end of study). A total of twenty-one (sixteen females and five males) participants completed the reduced-energy diet protocol (termed the energy-restricted group) and nineteen (thirteen females and six males) completed the pulse diet protocol (termed the pulse group). The mean ages for the energy-restricted group and the pulse group were 47.3 (SE 5.9) and 43.5 (SE 6.7) years, respectively (Table 2 ).

Self-reported compliance to the diets was high. Based on the pulse logs, seventeen out of nineteen of those in the pulse group ( $89.5 \%)$ ate all the pulse dishes. One subject recorded consuming $80 \%$ of the dishes and one recorded consuming $95 \%$ of the dishes; however, when meeting with the dietitian all forty participants said they consumed all of the dishes. In the pulse log, seven participants reported feeling bloated, one subject reported feeling flatulent and one reported an upset stomach. Each of these comments only occurred once for each subject. In addition, one subject

Table 2. Descriptive risk factors of male and female participants at study entry (Mean values with their standard errors)

\begin{tabular}{|c|c|c|c|c|c|c|}
\hline \multirow[b]{2}{*}{ Risk factors } & \multicolumn{2}{|c|}{ All participants ( $n$ 40) } & \multicolumn{2}{|c|}{ Females ( $n$ 29) } & \multicolumn{2}{|c|}{ Males $(n 11)$} \\
\hline & Mean & SE & Mean & SE & Mean & SE \\
\hline Age (years) & $45 \cdot 5$ & $1 \cdot 0$ & $45 \cdot 8$ & $1 \cdot 2$ & $44 \cdot 4$ & $2 \cdot 3$ \\
\hline Body weight (kg) & 88.7 & $2 \cdot 6$ & $82 \cdot 7$ & 2.4 & $104 \cdot 6$ & $4 \cdot 2$ \\
\hline BMI $\left(\mathrm{kg} / \mathrm{m}^{2}\right)$ & $32 \cdot 8$ & 0.7 & $32 \cdot 6$ & 0.8 & 33.5 & 1.3 \\
\hline Waist circumference $(\mathrm{cm})$ & $101 \cdot 8$ & $1 \cdot 7$ & $97 \cdot 8$ & 1.5 & $112 \cdot 4$ & $2 \cdot 8$ \\
\hline Systolic blood pressure $(\mathrm{mmHg})$ & 114.3 & $2 \cdot 6$ & $111 \cdot 3$ & $2 \cdot 9$ & $122 \cdot 4$ & $5 \cdot 1$ \\
\hline Diastolic blood pressure $(\mathrm{mmHg})$ & $71 \cdot 8$ & 1.5 & $70 \cdot 7$ & 1.7 & 74.8 & $2 \cdot 6$ \\
\hline Fasting glucose $(\mathrm{mmol} / \mathrm{l})$ & $5 \cdot 13$ & 0.11 & 5.02 & $0 \cdot 11$ & $5 \cdot 41$ & 0.28 \\
\hline Fasting insulin (pmol/l) & 81.06 & $6 \cdot 72$ & $77 \cdot 82$ & $7 \cdot 86$ & 89.64 & 13.44 \\
\hline Fasting C-peptide (pmol/l) & $849 \cdot 18$ & 38.58 & $835 \cdot 76$ & $46 \cdot 36$ & 884.55 & $71 \cdot 24$ \\
\hline $\mathrm{TC}(\mathrm{mmol} / \mathrm{l})$ & $5 \cdot 10$ & 0.15 & 5.07 & 0.18 & $5 \cdot 18$ & 0.23 \\
\hline $\mathrm{TAG}(\mathrm{mmol} / \mathrm{l})$ & 1.50 & 0.12 & 1.45 & 0.15 & 1.65 & 0.21 \\
\hline LDL (mmol/l) & $3 \cdot 25$ & $0 \cdot 12$ & $3 \cdot 17$ & 0.15 & 3.46 & 0.20 \\
\hline $\mathrm{HDL}(\mathrm{mmol} / \mathrm{l})$ & $1 \cdot 17$ & 0.06 & 1.24 & 0.07 & 0.96 & 0.08 \\
\hline $\mathrm{CRP}(\mathrm{mg} / \mathrm{l})$ & 4.59 & $1 \cdot 14$ & $5 \cdot 57$ & 1.54 & $2 \cdot 01$ & 0.40 \\
\hline $\mathrm{HbA} 1 \mathrm{c}(\%$ total $\mathrm{Hb})$ & 5.6 & 0.1 & $5 \cdot 6$ & 0.1 & $5 \cdot 6$ & 0.2 \\
\hline
\end{tabular}

TC, total cholesterol; CRP, C-reactive protein; $\mathrm{HbA1c}$, glycosylated $\mathrm{Hb}$. 
complained that the fiesta chilli was too spicy and another did not like the fiesta chilli and Moroccan chickpeas. Each dish was consumed twice over the study period, so when a participant did not like a dish, it was replaced with another dish containing the same pulse. Based on the $24 \mathrm{~h}$ food recalls, sixteen of those in the energy-restricted group reported that they reduced their energy intake, but only eleven had an energy restriction of $\geq 2093 \mathrm{~kJ}$ ( $\geq 500 \mathrm{kcal}$ ).

Although randomised, there were differences between the groups at baseline. There were no differences between the two dietary groups in age, height, weight, BMI, waist circumference, systolic blood pressure or any fasting blood measures. However, diastolic blood pressure was higher at baseline $(P=0.03)$ in the energy-restricted group compared with the pulse group. Also, postprandial blood glucose at $2 \mathrm{~h} \mathrm{(8.99}$ (SE 0.69) v. $6.87(\mathrm{se} 0.43) \mathrm{mmol} / \mathrm{l} ; P=0.02)$ and AUC (456.91 (SE 42.80) v. 326.00 (SE 35.09) $\mathrm{mmol} / 1 \times \mathrm{min} ; P=0.02)$ was higher for the energy-restricted group compared with the pulse group. Finally, reported $\mathrm{Na}$ intake was lower for the energy-restricted group compared with the pulse group (2036.4 (SE 265.8) v.3358.8 (sE 449.6) $\mathrm{mg}$, respectively; $P=0 \cdot 01$ ).

\section{Anthropometrics and blood pressure}

Waist circumference $(P<0 \cdot 0001)$ and systolic blood pressure $(P=0.005)$ decreased from week 1 to week 8 in both groups (Table 3 ). In the energy-restricted group waist circumference and systolic blood pressure decreased from 99.8 (SE 2.2) to 97.5 (SE 2.2) $\mathrm{cm}$ and $117 \cdot 2$ (SE 3.9) to $111 \cdot 3$ (sE 3.1) $\mathrm{mmHg}$, respectively. In the pulse group waist circumference and systolic blood pressure decreased from 104.0 (SE 2.5) to 102.3 (sE 2.4) $\mathrm{cm}$ and 111.2 (sE 3.5) to 106.7 (sE 2.6) $\mathrm{mmHg}$, respectively. There was no change in body weight, BMI or diastolic blood pressure (Table 3). The response to diet was not influenced by sex for any of the above-mentioned measures.

\section{Fasting blood measures}

HbA1c decreased in both groups from week 1 to week 8 $(P=0 \cdot 01)$ and there was a trend towards an interaction with diet $(P=0.09)$ (Table 4). In the energy-restricted group HbA1c decreased by $0.9 \%(5.69$ (SE 0.11$)$ to 5.64 (SE $0 \cdot 14) \%$ total $\mathrm{Hb}$ ) and decreased by $5.4 \%(5.53$ (SE 0.09$)$ to 5.23 (SE $0.07) \%$ total $\mathrm{Hb}$ ) in the pulse group. Changes in HDL and
C-peptide were influenced by a time $\times$ diet interaction ( $P=0.001$ and $P=0 \cdot 01$, respectively). HDL increased by $4.5 \%$ in the pulse group, while it decreased by $0.8 \%$ in the energy-restricted group (Fig. 1(a)). C-peptide increased in the pulse group by $12.3 \%$, but decreased by $7 \cdot 6 \%$ in the energy-restricted group (Fig. 1(b)). No statistically significant changes were found in TC, LDL, TAG, CRP, glucose or insulin (Table 4). Leptin increased in response to both diets $(P=0.001)$ (Table 5). It increased by $24 \%(23.72$ (SE 2.71) to $29.40(\mathrm{sE} 4.88) \mathrm{ng} / \mathrm{ml})$ in the energy-restricted diet group and by $53 \%(24.05(\mathrm{se} 3.16)$ to $36.75(\mathrm{sE} 5.14) \mathrm{ng} / \mathrm{ml})$ in the pulse diet group. There was no change in fasting adiponectin, GLP-1 or ghrelin (Table 5). The response to diet was not influenced by sex for any of the above-mentioned measures.

\section{Responses to a glucose load}

Overall there was an effect of diet $(P=0.004$ and $P=0.01$, respectively) on postprandial glucose AUC and glucose at $2 \mathrm{~h}$ response, with the energy-restricted group having a higher overall response. This may be explained by the fact that the energyrestricted group had a higher response at baseline. However, regardless of the effect of diet, blood glucose AUC decreased by $5.6 \%(424.33(\mathrm{se} 36.85)$ to $404.86(\mathrm{se} 32.87) \mathrm{mmol} / \mathrm{l} \times \mathrm{min})$ in the energy-restricted group and by $20.1 \%$ in the pulse group (326.00 (sE 35.09) to 260.61 (SE 29.72) $\mathrm{mmol} / \mathrm{l} \times \mathrm{min})$ $(P=0 \cdot 01)$ (Table 6). Change in the insulin AUC was influenced by a time $\times \operatorname{sex} \times$ diet interaction $(P=0 \cdot 008)$ (Fig. 2). Females in both the energy-restricted and pulse groups and males in the energy-restricted group had a decrease in insulin AUC (4.8, 13.9 and $24.2 \%$, respectively); however, males in the pulse group had an increased insulin AUC (27.3\%). There was a decrease in C-peptide at $2 \mathrm{~h}$ for both diet groups over the 8 week period $(P=0.04)$ (Table 6). C-peptide decreased by $7 \cdot 2 \%$ in the energy-restricted group $(3762 \cdot 81$ (SE 257.58) to 3492.81 (SE 249.91) pmol/l) and by $8.3 \%$ in the pulse group (3921.68 (se 317.15) to 3594.84 (se 238.42) pmol/1). There was a decrease in homeostasis model assessment of insulin resistance (HOMA-IR) AUC $(P=0 \cdot 01)$ and at $2 \mathrm{~h}(P<0.05)$ for both groups (Table 6$)$. In the energy-restricted group, HOMA-IR AUC decreased by $15.5 \%(219923.19$ ( $\mathrm{SE}$ 34871.15) to 185811.29 (SE 39698.71)) and at $2 \mathrm{~h}$ decreased by $14.9 \%$ (50.19 (SE 8.81) to 42.72 (SE 12.68)). In the pulse group, HOMA-IR AUC decreased by 22.3\% (188645.09 (SE 33637.41)

Table 3. Effect of time on anthropometric and blood pressure measurements following 8 weeks of study (Mean values with their standard errors)

\begin{tabular}{|c|c|c|c|c|c|c|c|c|c|}
\hline \multirow[b]{3}{*}{ Variables } & \multicolumn{6}{|c|}{ All participants } & & & \\
\hline & \multicolumn{2}{|c|}{ Week 1} & \multicolumn{2}{|c|}{ Week 4} & \multicolumn{2}{|c|}{ Week 8} & \multicolumn{3}{|c|}{$P$} \\
\hline & Mean & SE & Mean & SE & Mean & SE & Time & Diet & Timexdiet \\
\hline Weight (kg) & $88 \cdot 7$ & $2 \cdot 6$ & $88 \cdot 1$ & $2 \cdot 7$ & 87.99 & $2 \cdot 6$ & 0.28 & 0.08 & 0.15 \\
\hline BMI $\left(\mathrm{kg} / \mathrm{m}^{2}\right)$ & $32 \cdot 8$ & 0.7 & $32 \cdot 8$ & 0.7 & $32 \cdot 6$ & 0.7 & 0.07 & 0.44 & 0.20 \\
\hline Waist circumference (cm) & $101 \cdot 8^{a}$ & $1 \cdot 7$ & $101 \cdot 1^{a, b}$ & $1 \cdot 7$ & $99 \cdot 8^{\mathrm{b}}$ & $1 \cdot 7$ & $<0.0001$ & $0 \cdot 20$ & 0.32 \\
\hline Systolic blood pressure $(\mathrm{mmHg})$ & $114 \cdot 3^{a}$ & $2 \cdot 6$ & $113 \cdot 5^{\mathrm{a}}$ & $2 \cdot 3$ & $109 \cdot 2^{b}$ & $2 \cdot 0$ & 0.005 & 0.19 & 0.79 \\
\hline Diastolic blood pressure $(\mathrm{mmHg})$ & $71 \cdot 8$ & 1.4 & $72 \cdot 8$ & 1.5 & 71.5 & 1.4 & 0.34 & 0.18 & 0.08 \\
\hline
\end{tabular}

${ }^{\mathrm{a}, \mathrm{b}}$ Mean values within a row with unlike superscript letters were significantly different $(P<0.05$; two-way ANOVA; Tukey-Kramer post hoc test). 
Table 4. Effect of time on fasting blood measures following 8 weeks of study (Mean values with their standard errors)

\begin{tabular}{|c|c|c|c|c|c|c|c|c|c|}
\hline \multirow[b]{3}{*}{ Variables } & \multicolumn{6}{|c|}{ All participants } & & & \\
\hline & \multicolumn{2}{|c|}{ Week 1} & \multicolumn{2}{|c|}{ Week 4} & \multicolumn{2}{|c|}{ Week 8} & \multicolumn{3}{|c|}{$P$} \\
\hline & Mean & SE & Mean & SE & Mean & SE & Time & Diet & Timexdiet \\
\hline $\mathrm{TC}(\mathrm{mmol} / \mathrm{l})$ & $5 \cdot 10$ & 0.15 & $5 \cdot 20$ & 0.16 & $5 \cdot 10$ & 0.14 & 0.54 & 0.37 & 0.89 \\
\hline TAG (mmol/l) & 1.50 & $0 \cdot 12$ & 1.63 & 0.14 & 1.42 & $0 \cdot 12$ & 0.07 & 0.43 & $0 \cdot 13$ \\
\hline $\mathrm{LDL}(\mathrm{mmol} / \mathrm{l})$ & 3.25 & $0 \cdot 12$ & $3 \cdot 30$ & 0.13 & $3 \cdot 13$ & $0 \cdot 14$ & 0.28 & 0.78 & 0.56 \\
\hline $\mathrm{HDL}(\mathrm{mmol} / \mathrm{l})$ & $1 \cdot 17$ & 0.06 & $1 \cdot 17$ & 0.06 & $1 \cdot 19$ & 0.06 & 0.62 & 0.94 & 0.001 \\
\hline CRP (mg/l) & 4.59 & $1 \cdot 14$ & $4 \cdot 70$ & 0.88 & 3.52 & 0.65 & 0.08 & 0.97 & 0.45 \\
\hline $\mathrm{HbA} 1 \mathrm{c}(\%$ total $\mathrm{Hb})$ & $5 \cdot 61^{a}$ & 0.07 & $5 \cdot 53^{a, b}$ & 0.08 & $5 \cdot 47^{b}$ & 0.09 & 0.01 & 0.14 & 0.09 \\
\hline Glucose $(\mathrm{mmol} / \mathrm{l})$ & $5 \cdot 13$ & $0 \cdot 11$ & $5 \cdot 10$ & $0 \cdot 12$ & $5 \cdot 12$ & $0 \cdot 13$ & 0.90 & 0.13 & 0.79 \\
\hline Insulin (pmol/l) & 81.06 & $6 \cdot 72$ & $90 \cdot 48$ & $7 \cdot 74$ & 82.32 & 8.04 & 0.17 & 0.99 & 0.23 \\
\hline C-peptide (pmol/l) & $849 \cdot 18$ & 38.58 & 875.75 & 42.49 & 861.48 & 41.56 & 0.59 & 0.62 & 0.01 \\
\hline HOMA-IR & $3 \cdot 15$ & 0.30 & 3.48 & 0.34 & $3 \cdot 17$ & 0.35 & 0.24 & 0.64 & 0.26 \\
\hline
\end{tabular}

TC, total cholesterol, CRP, C-reactive protein, HbA1c, glycosylated Hb, HOMA-IR, homeostasis model assessment of insulin resistance.

a,b Mean values within a row with unlike superscript letters were significantly different $(P<0.05$; two-way ANOVA; Tukey-Kramer post hoc test).

to $146629 \cdot 73$ (sE $27083 \cdot 04))$ and at $2 \mathrm{~h}$ decreased by $25 \cdot 0 \%$ (44.60 (SE 10.07) to 33.44 (SE 5.85)). There was no effect on GLP-1 and ghrelin AUC or at $2 \mathrm{~h}$ (Table 6). The only measure in response to a glucose load measure over the 8-week period influenced by sex was insulin AUC.

\section{Dietary intake}

In the energy-restricted group, daily energy intake, carbohydrate intake and weight of food consumed decreased by $1793.6 \mathrm{~kJ}(8325.5$ (SE 575.7$)$ to $6531.8(\mathrm{SE} 589 \cdot 1) \mathrm{kJ})(428.4 \mathrm{kcal}$ (1988.5 (SE 137.5) to $1560 \cdot 1$ (SE $140 \cdot 7) \mathrm{kcal})$ ), 91.3 g (280.3 (SE 23.9) to 189.0 (SE 15.4) g) and $488.1 \mathrm{~g}(3004.9$ (SE 159.5) to $2516 \cdot 8$ (sE 168.2) g), respectively (Table 7). In the pulse group, daily energy intake, carbohydrate intake and weight of food consumed decreased by $1590 \cdot 1 \mathrm{~kJ}(8937 \cdot 6$ (SE $847 \cdot 4$ ) to $7347 \cdot 4$ (sE 692.1) kJ) $(379 \cdot 8 \mathrm{kcal}(2134.7$ (SE 202.4) to 1754.9 (SE 165.3) $\mathrm{kcal})$ ), $35 \cdot 3 \mathrm{~g}(270 \cdot 6$ (se $32 \cdot 1)$ to $235 \cdot 3$ (se 21.3) g) and $406 \cdot 1 \mathrm{~g}$ (3260.9 (SE 241.5) to 2854.8 (SE 202.1) g), respectively. In both groups, there was a trend towards a decrease in reported $\mathrm{g} / \mathrm{d}$ of sugar $(P=0.05)$ and fat $(P=0.07)$ intake (Table 7). In the energy-restricted group, sugar decreased from $92 \cdot 1$ (SE 8.9$)$ to $64.4(\mathrm{SE} 8.2) \mathrm{g} / \mathrm{d}$ and fat decreased from $63.3(\mathrm{SE} 6.2$ ) to 57.0 $(\mathrm{SE} 9 \cdot 3) \mathrm{g} / \mathrm{d}$. In the pulse group, sugar decreased from $90 \cdot 0$ (SE $14 \cdot 3$ ) to $79 \cdot 4(\operatorname{se~} 10 \cdot 4) \mathrm{g} / \mathrm{d}$ and fat decreased from $77 \cdot 4$ (SE 8.7) to $57.5(\operatorname{se~} 9.3) \mathrm{g} / \mathrm{d}$. Change in saturated fat intake $(\mathrm{g} / \mathrm{d})$ was influenced by a time $\times$ diet interaction $(P=0.02)$ and by a time $\times$ diet $\times$ sex interaction $(P=0.05)$. Females in both the energy-restricted $(21 \cdot 8(\mathrm{SE} 3 \cdot 1)$ to $14 \cdot 8(\mathrm{SE} 2 \cdot 3) \mathrm{g} / \mathrm{d})$ and pulse $(25 \cdot 1$ (SE 4.9$)$ to $17.6(\mathrm{se} 3.0) \mathrm{g} / \mathrm{d})$ groups and males in the energy-restricted group (15.1 (SE 3.4) to 13.9 (SE 3.4$) \mathrm{g} / \mathrm{d}$ ) had a decrease in saturated fat intake (g), while the males in the pulse group had a small increase (23.3 (SE 4.7) to $25.3(\operatorname{se~} 8.9) \mathrm{g} / \mathrm{d})$. There was no change in fibre or Na intakes over the 8-week trial; however, there was an overall effect of diet. Fibre intake $(\mathrm{g} / \mathrm{d})$ was higher in the pulse group compared with the energy-restricted group (28.9 (SE 2.1) v.21.4 (SE 1.4) g/d; $P=0 \cdot 02$ ). This can be explained by a trend towards a change in fibre intake over the 8 weeks, which was influenced by diet (time $\times$ diet interaction; $P=0 \cdot 08)$. In the energy-restricted group, fibre intake (g) decreased by $12 \%(24.9$ (SE 3.3) to $22 \cdot 0$ (SE $2 \cdot 0) \mathrm{g} / \mathrm{d}$ ), while it increased by $5 \%(27 \cdot 0$ ( $\mathrm{SE} 3 \cdot 7)$ to 28.3 ( $\mathrm{sE}$ $3 \cdot 1) \mathrm{g} / \mathrm{d})$ in the pulse group. Na intake $(\mathrm{g} / \mathrm{d})$ was higher overall for the pulse group $(P=0 \cdot 01)$, but this is explained by differences found at baseline. There was no change in protein intake $(\mathrm{g} / \mathrm{d})$. Only change in saturated fat intake $(\mathrm{g} / \mathrm{d})$ over time was influenced by sex.

Although both groups decreased their carbohydrate intake $(\mathrm{g} / \mathrm{d})$, change in the proportion of energy (\% energy) from carbohydrate was influenced by diet (time $\times$ diet interaction; $P=0.04)$. In response to the energy-restricted diet, there was a decrease in percentage energy from carbohydrate from $56 \cdot 1$ to $50 \cdot 8 \%$; however, there was an increase from $50 \cdot 2$ to $54.5 \%$ in response to the pulse diet. Despite no difference in the amount consumed $(\mathrm{g} / \mathrm{d})$, there was an effect on percentage of energy from PUFA, which was influenced by diet (time $x$ diet interaction; $P=0.02$ ). In response to the energy-restricted diet, there was an increase in percentage energy from polyunsaturated fat from 4.3 (SE 0.6) to 5.9 (SE 0.9) \%, but a decrease from $4.4(\operatorname{se} 0.6)$ to $3 \cdot 1(\operatorname{se~} 0.4) \%$ in response to the pulse diet. There was no change in percentage of energy from sugar, fat, saturated fat or protein (Table 7). None of the above-mentioned responses was influenced by sex over the 8-week period.

\section{Discussion}

Regularly consuming pulses in an ad libitum diet was as effective at reducing risk factors of the MetSyn as an energyrestricted diet implemented through dietary counselling. Both the pulse and energy-restricted diets resulted in a reduction in reported energy intakes, waist circumference, systolic blood pressure, HbA1c, as well as improved blood glucose control and insulin sensitivity (decreased insulin resistance). In addition, both diets decreased postprandial C-peptide and increased fasting plasma leptin. However, only the pulse diet increased HDL and fasting C-peptide and the effects on insulin AUC were not only influenced by diet, but also sex. Neither diet affected TC, LDL, TAG, CRP, adiponectin, 

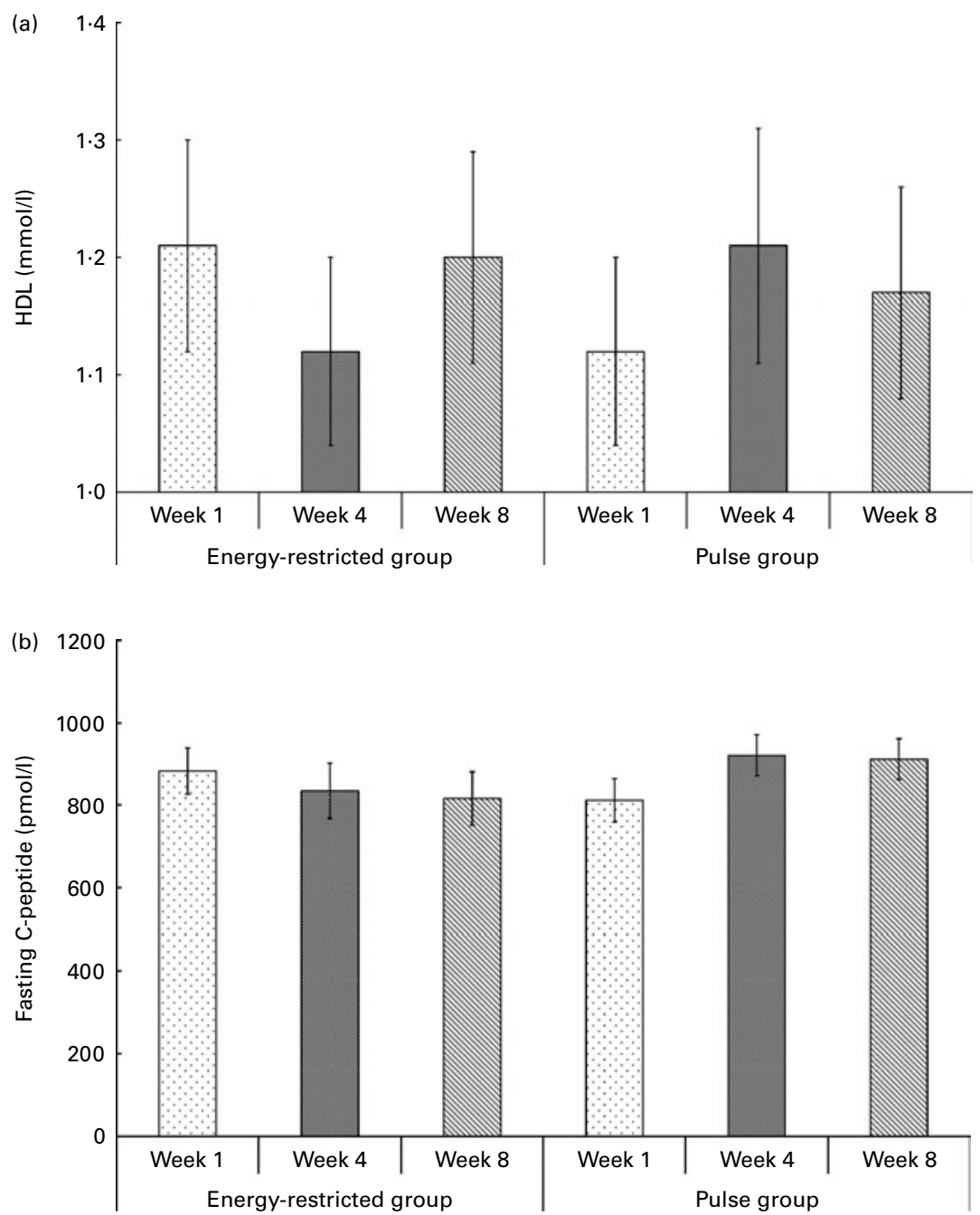

Fig. 1. Influence of diet on changes in fasting HDL (a) and C-peptide (b) over the 8-week study period. Participants received either an energy-restricted ( $n$ 21) or a pulse $(n 19)$ diet. Values are means, with standard errors represented by vertical bars. For HDL, there was a time $\times$ diet interaction $(P=0.001$; two-way ANOVA). For C-peptide there was a time $\times$ diet interaction ( $P=0.01$; two-way ANOVA).

GLP-1 or ghrelin. Thus, it can be suggested that while both diets led to reduced energy intakes and waist circumference, improved glycaemic control and insulin sensitivity, the pulse diet, perhaps due to some functional properties of pulses, led to additional benefits beyond a reduction in energy intake.

Many of the decreases in risk factors of the MetSyn are associated with reduced energy intake and body weight or changes in diet composition ${ }^{(6)}$. Thus, it is difficult to determine which of these were primary in the present study. Although a major limitation of the present study was that participants completed only three $24 \mathrm{~h}$ food recalls and lower energy intake was reported at week 8 , the lack of change in body weight indicates that the $24 \mathrm{~h}$ recall did not reflect habitual intakes of energy. The energy-restricted group lost a mean

Table 5. Effect of time on fasting satiety-regulating hormones following 8 weeks of study

(Mean values with their standard errors)

\begin{tabular}{|c|c|c|c|c|c|c|c|}
\hline \multirow[b]{3}{*}{ Variable } & \multicolumn{4}{|c|}{ All participants } & & & \\
\hline & \multicolumn{2}{|c|}{ Week 1} & \multicolumn{2}{|c|}{ Week 8} & \multicolumn{3}{|c|}{$P$} \\
\hline & Mean & SE & Mean & SE & Time & Diet & Timexdiet \\
\hline Adiponectin (ng/ml) & $9 \cdot 79$ & 0.79 & $10 \cdot 53$ & 1.05 & 0.10 & 0.84 & $0 \cdot 24$ \\
\hline Leptin (ng/ml) & $23 \cdot 88^{a}$ & 2.05 & $32 \cdot 89^{b}$ & 3.54 & 0.001 & 0.48 & 0.18 \\
\hline GLP-1 (pmol/l) & 3.46 & 0.71 & 3.53 & 0.71 & 0.86 & 0.26 & 0.72 \\
\hline Ghrelin (pg/ml) & $253 \cdot 46$ & $19 \cdot 48$ & $244 \cdot 83$ & $18 \cdot 40$ & 0.68 & 0.11 & 0.15 \\
\hline
\end{tabular}

GLP-1, glucagon-like peptide-1.

${ }^{a, b}$ Mean values within a row with unlike superscript letters were significantly different $(P<0.05$; two-way ANOVA; Tukey-Kramer post hoc test). 
Table 6. Effect of time on the response of glucose, insulin, homeostasis model assessment of insulin resistance (HOMA-IR) and glucagon-like peptide-1 (GLP-1) to an oral glucose load over $2 \mathrm{~h}$ following 8 weeks of study (Mean values with their standard errors)

\begin{tabular}{|c|c|c|c|c|c|c|c|}
\hline \multirow[b]{3}{*}{ Variables } & \multicolumn{4}{|c|}{ All participants } & & & \\
\hline & \multicolumn{2}{|c|}{ Week 1} & \multicolumn{2}{|c|}{ Week 8} & \multicolumn{3}{|c|}{$P$} \\
\hline & Mean & SE & Mean & SE & Time & Diet & Timexdiet \\
\hline Glucose AUC $(\mathrm{mmol} / / \times \mathrm{min})$ & $377 \cdot 63^{a}$ & $26 \cdot 41$ & $336.34^{\mathrm{b}}$ & 24.85 & 0.01 & 0.004 & 0.73 \\
\hline $2 \mathrm{~h}$ Glucose $(\mathrm{mmol} / \mathrm{l})$ & 7.98 & 0.45 & 7.31 & 0.35 & 0.09 & 0.01 & 0.30 \\
\hline Insulin AUC (pmol/l × min) & $67735 \cdot 13$ & $5696 \cdot 28$ & 63959.00 & 5986.79 & 0.47 & 0.28 & $0 \cdot 10$ \\
\hline $2 \mathrm{~h}$ Insulin (pmol/l) & $754 \cdot 15$ & 85.56 & 635.55 & 91.40 & 0.06 & 0.97 & 0.76 \\
\hline C-peptide AUC $(\mathrm{pmol} / \mathrm{I} \times \mathrm{min})$ & $266070 \cdot 26$ & $11479 \cdot 20$ & $262955 \cdot 28$ & 11267.92 & 0.55 & 0.23 & 0.82 \\
\hline 2 h C-peptide $(\mathrm{pmol} / \mathrm{l})$ & $3838 \cdot 28^{\mathrm{a}}$ & $200 \cdot 19$ & $3541 \cdot 28^{\mathrm{b}}$ & 171.30 & 0.04 & 0.71 & 0.84 \\
\hline HOMA-IR AUC & $205066 \cdot 09^{a}$ & $24118 \cdot 32$ & $167200 \cdot 05^{\mathrm{b}}$ & 24391.05 & 0.01 & 0.46 & 0.77 \\
\hline $2 \mathrm{~h}$ HOMA-IR & $47.54^{\mathrm{a}}$ & 6.83 & $38 \cdot 31^{\mathrm{b}}$ & $7 \cdot 17$ & $<0.05$ & 0.46 & 0.69 \\
\hline GLP-1 AUC (pmol/l × min) & 231.86 & $30 \cdot 71$ & 262.36 & $41 \cdot 70$ & 0.57 & 0.87 & 0.32 \\
\hline 2h GLP-1 (pmol/l) & 4.70 & 0.79 & $5 \cdot 28$ & 0.77 & 0.23 & 0.29 & 0.50 \\
\hline Ghrelin AUC (pg/ml × min) & $-12666 \cdot 04$ & $1992 \cdot 54$ & -9223.59 & $1297 \cdot 24$ & 0.14 & 0.09 & 0.44 \\
\hline 2h Ghrelin (pg/ml) & $162 \cdot 32$ & 14.80 & 173.94 & 14.99 & 0.46 & 0.99 & 0.14 \\
\hline
\end{tabular}

${ }^{a, b}$ Mean values within a row with unlike superscript letters were significantly different $(P<0.05$; two-way ANOVA; Tukey-Kramer post hoc test).

of $1.2 \mathrm{~kg}$ but not the expected weight loss of $3 \cdot 1 \mathrm{~kg}$ based on the dietary records, and the pulse group lost a mean of $0.2 \mathrm{~kg}$ compared with an expected loss of $2 \cdot 8 \mathrm{~kg}$ based on their dietary records. On the other hand, the decrease in waist circumference suggests a decrease in abdominal fat, supporting a reduction in energy intake. Despite no difference in body weight and BMI, this reduction in waist circumference is potentially significant. Studies have confirmed that waist circumference is an important risk factor in the definition of the MetSyn ${ }^{(20)}$ and an important tool in assessing risk of CVD, type 2 diabetes and/or mortality ${ }^{(20-24)}$. In addition, these relationships with waist circumference are stronger than with $\mathrm{BMI}^{(21)}$ and independent of $\mathrm{BMI}^{(23,24)}$. It has been suggested that reductions in waist circumference should be a primary goal of strategies designed to reduce risk factors associated with the MetSyn ${ }^{(20)}$. No other studies have reported the effects of pulse consumption on waist circumference; however, consistent with the present study, most of them report no effect on body weight ${ }^{(13,25-28)}$.

Based on the dietary records at week 8 , it can be suggested that all participants attempted to improve the quality of their diets, a factor that may have accounted for reductions in risk factors. Both groups reported a significant decrease in energy $(\mathrm{kJ} / \mathrm{d})$ and carbohydrates $(\mathrm{g} / \mathrm{d})$ intakes and reported a trend towards a decrease in sugar $(\mathrm{g} / \mathrm{d})$ and total fat $(\mathrm{g} / \mathrm{d})$ intake. In addition, reported fibre intakes $(\mathrm{g} / \mathrm{d})$ were higher

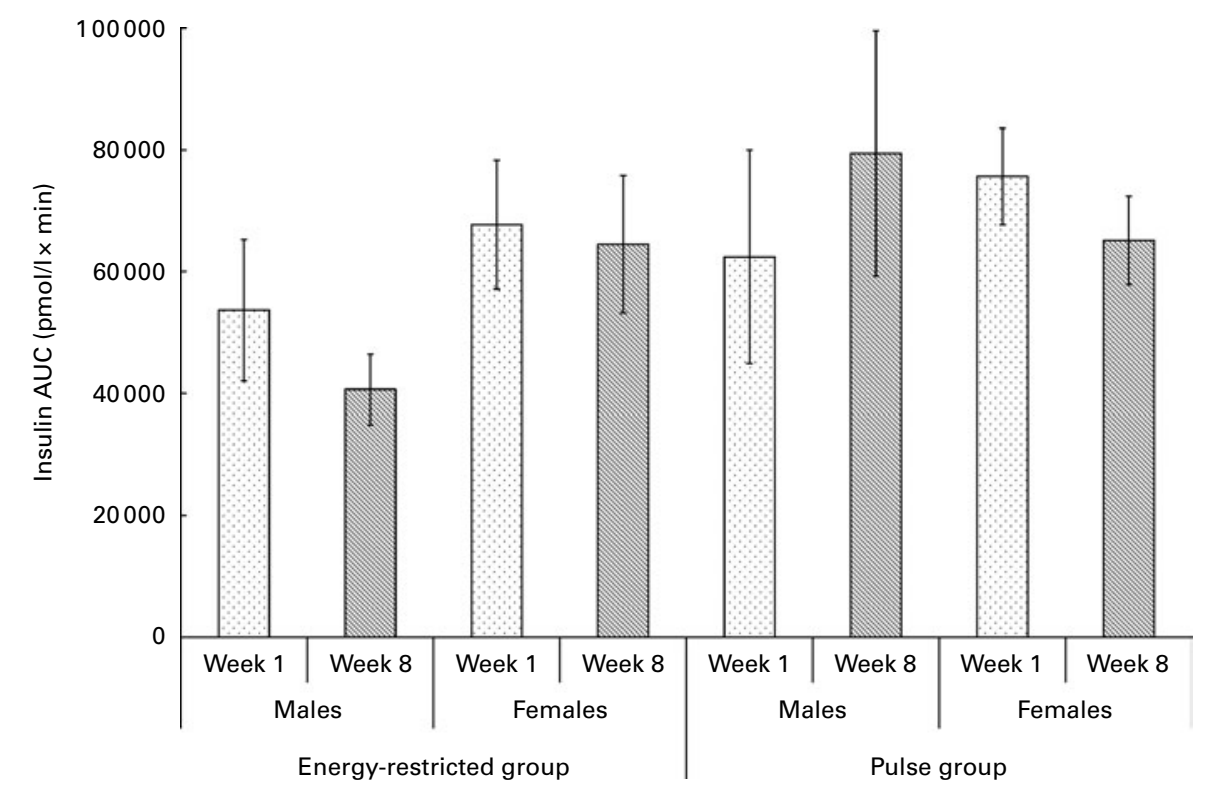

Fig. 2. Influence of both diet and sex on changes in postprandial insulin AUC response to a glucose load over the 8-week study period. Participants received either an energy-restricted $(n 21)$ or a pulse $(n 19)$ diet. Values are means, with standard errors represented by vertical bars. There was a time $\times$ diet $\times$ sex interaction $(P=0.008$; three-way ANOVA). 
Table 7. Effect of time on daily dietary nutrient intakes following 8 weeks of study (Mean values with their standard errors)

\begin{tabular}{|c|c|c|c|c|c|c|c|c|c|}
\hline \multirow[b]{3}{*}{ Variables } & \multicolumn{6}{|c|}{ All participants } & & & \\
\hline & \multicolumn{2}{|c|}{ Week 1} & \multicolumn{2}{|c|}{ Week 4} & \multicolumn{2}{|c|}{ Week 8} & \multicolumn{3}{|c|}{$P$} \\
\hline & Mean & SE & Mean & SE & Mean & SE & Time & Diet & Timexdiet \\
\hline \multicolumn{10}{|l|}{ Energy } \\
\hline $\mathrm{kJ} / \mathrm{d}$ & $8616 \cdot 4^{a}$ & $499 \cdot 1$ & $7364 \cdot 2^{b}$ & $450 \cdot 5$ & $1619 \cdot 5^{b}$ & $450 \cdot 1$ & 0.006 & 0.42 & 0.92 \\
\hline $\mathrm{kcal} / \mathrm{d}$ & $2058 \cdot 0^{\mathrm{a}}$ & $119 \cdot 2$ & $1758.9^{\mathrm{b}}$ & $107 \cdot 6$ & $1652 \cdot 7^{\mathrm{b}}$ & $107 \cdot 5$ & 0.006 & 0.42 & 0.92 \\
\hline Total weight (g/d) & $3126 \cdot 5^{a}$ & 141.6 & $2716 \cdot 3^{a, b}$ & 191.6 & $2677 \cdot 4^{b}$ & $157 \cdot 5$ & 0.02 & 0.43 & 0.57 \\
\hline Total carbohydrate $(\mathrm{g} / \mathrm{d})$ & $275 \cdot 7^{\mathrm{a}}$ & 19.5 & $236 \cdot 4^{a, b}$ & $16 \cdot 2$ & $211.0^{\mathrm{b}}$ & $13 \cdot 3$ & 0.003 & 0.22 & 0.15 \\
\hline Total carbohydrate (\% of energy) & $53 \cdot 3$ & $2 \cdot 2$ & 54.0 & 1.8 & $52 \cdot 6$ & $2 \cdot 1$ & 0.74 & 0.74 & 0.04 \\
\hline Sugar $(g / d)$ & $91 \cdot 1$ & $8 \cdot 1$ & $87 \cdot 1$ & 8.0 & 71.5 & $6 \cdot 6$ & 0.05 & 0.46 & 0.51 \\
\hline Sugar (\% of energy) & $17 \cdot 3$ & 1.0 & $20 \cdot 2$ & 1.6 & $17 \cdot 7$ & 1.3 & 0.20 & 0.69 & 0.76 \\
\hline Fibre $(g / d)$ & $25 \cdot 9$ & $2 \cdot 4$ & 23.9 & $2 \cdot 4$ & $25 \cdot 0$ & 1.9 & 0.84 & 0.02 & 0.08 \\
\hline Protein $(\mathrm{g} / \mathrm{d})$ & 87.5 & $6 \cdot 2$ & 83.5 & $4 \cdot 2$ & 83.1 & $6 \cdot 2$ & 0.72 & 0.43 & 0.54 \\
\hline Protein (\% of energy) & $17 \cdot 7$ & $1 \cdot 1$ & $20 \cdot 0$ & 1.1 & $20 \cdot 4$ & 0.9 & $0 \cdot 10$ & 0.99 & 0.12 \\
\hline Fat $(g / d)$ & $70 \cdot 1$ & $5 \cdot 3$ & $55 \cdot 1$ & 5.5 & $57 \cdot 2$ & 6.5 & 0.07 & 0.62 & 0.51 \\
\hline Fat (\% of energy) & 30.5 & 1.6 & $26 \cdot 8$ & 1.6 & 29.3 & 1.8 & 0.19 & 0.71 & 0.29 \\
\hline Saturated fat $(\mathrm{g} / \mathrm{d})$ & $22 \cdot 2$ & $2 \cdot 2$ & $18 \cdot 6$ & $2 \cdot 3$ & $17 \cdot 2$ & 1.9 & 0.31 & 0.39 & 0.02 \\
\hline Saturated fat (\% of energy) & $9 \cdot 3$ & 0.6 & 8.9 & 0.7 & $8 \cdot 8$ & 0.6 & 0.80 & 0.68 & 0.23 \\
\hline PUFA (g/d) & 9.7 & $1 \cdot 1$ & $8 \cdot 1$ & $1 \cdot 2$ & 9.0 & 1.6 & 0.56 & 0.49 & 0.11 \\
\hline PUFA (\% of energy) & 4.4 & 0.4 & 4.0 & 0.5 & 4.6 & 0.6 & 0.49 & 0.15 & 0.02 \\
\hline $\mathrm{Na}(\mathrm{mg} / \mathrm{d})$ & 2664.5 & 273.0 & 2670.9 & $220 \cdot 9$ & $2598 \cdot 0$ & 237.5 & 0.96 & 0.02 & 0.44 \\
\hline
\end{tabular}

a,b Mean values within a row with unlike superscript letters were significantly different $(P<0.05$; two-way ANOVA; Tukey-Kramer post hoc test).

in the pulse group and over the 8 weeks increased in the pulse group by $5 \%$, but decreased in the energy-restricted group by $12 \%$. It is likely that the high compliance (89.5\%) of the incorporation of pulses into the diet resulted in replacement of foods that are less nutritious and added many nutritive and non-nutritive compounds that have health benefits. However, it is important to note that although both groups met with the dietitian and those receiving counselling for energy restriction spent more time and received more guidance, a limitation was that all participants were aware that they were in a dietary study. In the case of the pulse group, the food recalls and pulse record would reinforce their belief that there was interest in their dietary behaviour. Thus, it is possible that interaction with a dietitian and participation in the study might have resulted in dietary changes. In the energy-restricted group, the dietary counselling for energy reduction and improvements in diet quality (reductions in sugar, fat and alcohol intakes and increases in fruit and vegetable intakes) most probably accounted for better food choices.

Although the weakness in our dietary assessment leaves uncertain the causes of the reduction in risk factors, the effects of the pulse diet on glycaemic control and HDL were greater than in the diet-counselled group, suggesting that the benefit to pulses extended beyond the effects of energy reduction alone. In response to the pulse diet, postprandial blood glucose AUC decreased by $20 \cdot 1 \%$, while there was only a $5 \cdot 6 \%$ decrease in response to the energy-restricted diet. In addition, there was a $0.3 \%$ absolute decrease in HbA1c ( 5.53 to $5.23 \%$ total $\mathrm{Hb}$ ) in response to the pulse diet, while there was only a $0.05 \%$ decrease in response to the energy-restricted diet. In support of our findings, a recent meta-analysis found that pulses when consumed alone lower fasting blood glucose compared with diets without pulses and when incorporated into a low-GI or high-fibre diet, they lower fasting blood glucose and/or glycosylated blood proteins (including HbA1c) compared with higher-GI or low-fibre diets ${ }^{(14)}$.

Improvements in blood glucose control in response to pulse consumption above energy restriction could be due to specific dietary changes. As previously stated, both diets led to a decrease in reported energy intake, which was mainly the result of a decrease in carbohydrate consumption. In response to the pulse diet, this dietary change was probably due to a replacement of higher-energy density and carbohydrate foods. Also, it has been proposed that improved blood glucose control in response to pulses is due to their insulin-sensitising effects ${ }^{(14)}$, which could be due to specific nutrient (protein, fibre, resistant starch) and/or non-nutrient component(s) found in pulses. Finally, pulses are low-GI foods and it has been proposed that data from acute and chronic feeding trials suggest that they improve blood glucose control by lowering the GI of the diet and slowing absorption $^{(14)}$.

An improvement in blood lipids by the pulse diet was indicated by an increase in HDL. HDL increased by $4.5 \%$ in the pulse group, while it decreased by $0.8 \%$ in the energyrestricted group. The reported effects of pulse consumption (two to five cups/week for 3-16 weeks) on HDL are inconsistent, with some studies showing no effect ${ }^{(25-32)}$, and others showing a reduction ${ }^{(33,34)}$ or an increase in $\mathrm{HDL}^{(35)}$. Although HDL was increased, neither the pulse nor the energy-restricted diet affected other blood lipids, including TC and LDL. These results contrast with a recent meta-analysis of ten randomised controlled trials evaluating the effects of pulse consumption (two to five cups/d for 3-8 weeks) on blood lipids. Only studies with a non-pulse diet control group and similar total energy and macronutrient values in the control and pulse 
diets were included. They found regular pulse consumption (beans, lentils, peas, chickpeas) reduced TC and LCL with no effect on $\mathrm{HDL}^{(13)}$. However, despite the findings of the meta-analysis, as with HDL, it is important to note that longterm studies have found conflicting findings; some show that regular consumption of pulses has no effect ${ }^{(29,35)}$, while others show a reduction in TC and/or LDL ${ }^{(25-28,30-34)}$.

The effects on the postprandial insulin response and insulin secretion were also dependent upon the type of diet; however, whether one response is advantageous over another requires clarification. The postprandial insulin AUC response was influenced by both diet and sex. In both groups, females had a decrease in insulin AUC; however, in males there was a decrease in insulin AUC in response to the energy-restricted diet, but an increase in the pulse group. These effects could be in response to increased insulin secretion. Although only a trend (time $\times \operatorname{diet} \times \operatorname{sex}$ interaction; $P=0.07)$, the C-peptide AUC response followed the same pattern as insulin AUC.

The effects on insulin secretion in the fasting and postprandial states were different in response to the pulse diet, but the same for the energy-restricted diet. Fasting C-peptide was increased in the pulse diet group by $12.3 \%$, indicating increased insulin secretion, while it was decreased in the energy-restricted diet group by $7 \cdot 6 \%$. Postprandial C-peptide at $2 \mathrm{~h}$ was reduced in both the pulse (8.3\%) and energyrestricted $(7 \cdot 2 \%)$ groups. However, despite these changes in insulin precursor secretion, there was no effect of diet on fasting or postprandial $2 \mathrm{~h}$ insulin concentrations. This may be explained by the fact that C-peptide has a longer half-life (20-30 min) compared with that of insulin $(5 \mathrm{~min})$, and this in turn reflects a five times higher concentration of C-peptide in plasma compared with insulin ${ }^{(36)}$. In addition, C-peptide is not only an indicator of insulin secretion, but it has been shown to have physiological effects, including increasing glucose utilisation ${ }^{(37)}$. However, whether changes in C-peptide contributed to the changes seen in blood glucose response requires further study.

Both diets improved postprandial insulin sensitivity (reduced insulin resistance) as is indicated by a decrease in postprandial HOMA-IR at $2 \mathrm{~h}$ and HOMA-IR AUC. This reduction in HOMA-IR supports the suggestion that improved blood glucose control in response to pulses is due to their insulin-sensitising effects ${ }^{(14)}$. The effects of pulses on insulin and HOMA-IR in previous studies are conflicting. Consumption of an ad libitum diet supplemented with chickpeas (about 4.5 cups/week) for 12 weeks decreased fasting insulin and increased insulin sensitivity (decreased HOMA-IR) in normoglycaemic adults ${ }^{(28)}$. However, other studies have found that regular consumption of pulses, chickpeas (about 3.5 cups/week) plus chickpea products (30\% chickpea flour) for $5-6$ weeks $^{(11,32)}$ or beans $\left(3.5\right.$ cups/week) for 8 weeks ${ }^{(26,27)}$ does not influence fasting insulin, postprandial insulin and/ or insulin sensitivity.

Both diets reduced systolic blood pressure, consistent with epidemiological research that indicates that regular baked bean consumption is associated with lower systolic blood pressure $^{(38)}$. In contrast, daily consumption of half a cup of baked white beans by normotensive hypercholesterolaemic adults $^{(26)}$ or half a cup of pinto beans by normotensive mildly insulin-resistant adults ${ }^{(27)}$ over 8 weeks had no effect on blood pressure. The decrease in blood pressure in our participants may be explained by many factors, including a reduction in waist circumference ${ }^{(39)}$, changes in dietary intakes $^{(38)}$ and a familiarisation with study procedures and investigators.

The effects of pulse consumption on waist circumference, blood glucose, insulin and HOMA-IR are not explained by changes in GLP-1, adiponectin, leptin and/or ghrelin. GLP-1, adiponectin, leptin and ghrelin are hormones involved in food intake regulation ${ }^{(40)}$. Also, GLP-1 is a powerful incretin hormone that stimulates insulin synthesis and release ${ }^{(41)}$, while adiponectin has been shown to be related to insulin resistance ${ }^{(42)}$. There were no changes in GLP-1, adiponectin or ghrelin and both diets increased leptin. An increase in leptin is unexpected because it has been consistently shown that leptin decreases in response to energy restriction; however, in the majority of those studies the dietary interventions were longer, energy restriction was greater and/or there was significant loss of body weight ${ }^{(43-48)}$.

Results from previous studies on risk factors of the MetSyn have been inconsistent. Conflicting findings could be for a variety of reasons. These include: variations in the length of intervention (3-16 weeks), type of dietary guidance (ad libitum $v$. controlled energy and/or macronutrient intakes), type of control diets (canned carrots, canned spaghetti, wheat-based products or no control) and health status of participants studied (healthy, normoglycaemic, hyperglycaemic, insulin resistant, hypercholesterolaemic, pre-MetSyn, diabetes, obesity, etc.), as well as the type (beans, chickpeas, lentils, peas or mixed pulses) and amount of pulses (two to five cups/week) supplemented $^{(11,26-28,30,35)}$. However, despite these inconsistencies, multiple studies, including the present study, have shown that the simple incorporation of pulses into the diet is beneficial for the improvement in risk factors of the MetSyn. Also, in addition to the advantages of the pulse diet seen in the present study, it is likely that incorporation of pulses into the diet would replace foods that are less nutritious and add nutritive and non-nutritive compounds that have health benefits beyond those measured.

In conclusion, five cups of pulses/week incorporated into the participants' habitual diet spontaneously led to health benefits without dietary counselling and these benefits were similar to those seen with energy restriction dietary counselling. Also, there were further benefits to pulse consumption compared with an energy-restricted diet, including greater improvements in glycaemic control and increased HDL. From these findings, it can be speculated that the continuation of the pulse diet beyond 8 weeks would have led to a further reduction in waist circumference and improvements in postprandial blood glucose and HDL, and eventual weight loss (based on $24 \mathrm{~h}$ food recalls), which would reduce the risk of the MetSyn and related chronic diseases. Thus, these results support the recommendation of regularly consuming pulses for the prevention or management of risk factors of the MetSyn. 


\section{Acknowledgements}

This research was funded as part of the Pulse Innovation Project, through Canada's Agricultural Policy Framework (APF), a Federal-Provincial-Territorial initiative. We would also like to acknowledge the assistance of Dr France Cho, Michelle Liu, Chris Smith and Iryna Sydorska. R. C. M. was responsible for recipe development, coordination of the study, managing students and research assistants, data analysis and writing of the manuscript. B. L. L. was involved in the coordination of the study, sample collection, analysis of hormones, managing students and research assistants, communication with the funding agency and reviewing of the manuscript. S. P. was responsible for subject recruitment, conducting study sessions, sample collection and reviewing the manuscript. M. N. was involved in data analysis and reviewing of the manuscript. A. H. was involved in the conceptualisation and design of the study and subject recruitment. G. H. A. was the principal investigator responsible for the conceptualisation and design of the study, coordination of the research team and reviewing of the manuscript. None of the authors has any conflicts of interest.

\section{References}

1. Alberti KG, Eckel RH, Grundy SM, et al. (2009) Harmonizing the metabolic syndrome: a joint interim statement of the International Diabetes Federation Task Force on Epidemiology and Prevention; National Heart. Lung, and Blood Institute; American Heart Association; World Heart Federation; International Atherosclerosis Society; and International Association for the Study of Obesity. Circulation 120, 1640-1645.

2. Lakka HM, Laaksonen DE, Lakka TA, et al. (2002) The metabolic syndrome and total and cardiovascular disease mortality in middle-aged men. JAMA 288, 2709-2716.

3. Grundy SM (2004) Obesity, metabolic syndrome, and cardiovascular disease. J Clin Endocrinol Metab 89, 2595-2600.

4. Hunt KJ, Resendez RG, Williams K, et al. (2004) National Cholesterol Education Program versus World Health Organization metabolic syndrome in relation to all-cause and cardiovascular mortality in the San Antonio Heart Study. Circulation 110, 1251-1257.

5. Malik S, Wong ND, Franklin SS, et al. (2004) Impact of the metabolic syndrome on mortality from coronary heart disease, cardiovascular disease, and all causes in United States adults. Circulation 110, 1245-1250.

6. Abete I, Astrup A, Martinez JA, et al. (2010) Obesity and the metabolic syndrome: role of different dietary macronutrient distribution patterns and specific nutritional components on weight loss and maintenance. Nutr Rev 68, 214-231.

7. Das SK, Gilhooly CH, Golden JK, et al. (2007) Long-term effects of 2 energy-restricted diets differing in glycemic load on dietary adherence, body composition, and metabolism in CALERIE: a 1-y randomized controlled trial. Am J Clin Nutr 85, 1023-1030.

8. Hill JO, Thompson H \& Wyatt H (2005) Weight maintenance: what's missing? J Am Diet Assoc 105, S63-S66.

9. Tsezou A, Karayannis G, Giannatou E, et al. (2008) Association of renin-angiotensin system and natriuretic peptide receptor A gene polymorphisms with hypertension in a Hellenic population. J Renin Angiotensin Aldosterone Syst 9, 202-207.
10. Jenkins DJ, Wolever TM, Taylor RH, et al. (1980) Exceptionally low blood glucose response to dried beans: comparison with other carbohydrate foods. Br Med J 281, 578-580.

11. Nestel P, Cehun M \& Chronopoulos A (2004) Effects of longterm consumption and single meals of chickpeas on plasma glucose, insulin, and triacylglycerol concentrations. Am J Clin Nutr 79, 390-395.

12. Wong CL, Mollard RC, Zafar TA, et al. (2009) Food intake and satiety following a serving of pulses in young men: effect of processing, recipe, and pulse variety. J Am Coll Nutr $\mathbf{2 8}$, 543-552.

13. Bazzano LA, Thompson AM, Tees MT, et al. (2009) Non-soy legume consumption lowers cholesterol levels: a metaanalysis of randomized controlled trials. Nutr Metab Cardiovasc Dis 21, 94-103.

14. Sievenpiper JL, Kendall CW, Esfahani A, et al. (2009) Effect of non-oil-seed pulses on glycaemic control: a systematic review and meta-analysis of randomised controlled experimental trials in people with and without diabetes. Diabetologia 52, 1479-1495.

15. Ford ES, Giles WH \& Mokdad AH (2004) Increasing prevalence of the metabolic syndrome among U.S. adults. Diabetes Care 27, 2444-2449.

16. Brien SE \& Katzmarzyk PT (2006) Physical activity and the metabolic syndrome in Canada. Appl Physiol Nutr Metab 31, 40-47.

17. Lin WY, Yang WS, Lee LT, et al. (2006) Insulin resistance, obesity, and metabolic syndrome among non-diabetic preand post-menopausal women in North Taiwan. Int J Obes (Lond) 30, 912-917.

18. Liu J, Hanley AJ, Young TK, et al. (2006) Characteristics and prevalence of the metabolic syndrome among three ethnic groups in Canada. Int J Obes (Lond) 30, 669-676.

19. Liu J, Young TK, Zinman B, et al. (2006) Lifestyle variables, non-traditional cardiovascular risk factors, and the metabolic syndrome in an Aboriginal Canadian population. Obesity (Silver Spring) 14, 500-508.

20. Katzmarzyk PT, Janssen I, Ross R, et al. (2006) The importance of waist circumference in the definition of metabolic syndrome: prospective analyses of mortality in men. Diabetes Care 29, 404-409.

21. Balkau B, Deanfield JE, Després JP, et al. (2007) International Day for the Evaluation of Abdominal Obesity (IDEA): a study of waist circumference, cardiovascular disease, and diabetes mellitus in 168,000 primary care patients in 63 countries. Circulation 116, 1942-1951.

22. Yusuf S, Hawken S, Ounpuu S, et al. (2004) Effect of potentially modifiable risk factors associated with myocardial infarction in 52 countries (the INTERHEART study): casecontrol study. Lancet 364, 937-952.

23. Pischon T, Boeing H, Hoffman K, et al. (2008) General and abdominal adipocity and risk of death in Europe. $N$ Engl J Med 359, 2105-2120.

24. Jacobs EJ, Newton CC, Wang Y, et al. (2010) Waist circumference and all-cause mortality in a large US cohort. Arch Int Med 170, 1293-1301.

25. Jenkins DJ, Wong GS, Patten R, et al. (1983) Leguminous seeds in the dietary management of hyperlipidemia. $A m \mathrm{~J}$ Clin Nutr 38, 567-573.

26. Winham DM \& Hutchins AM (2007) Baked bean consumption reduces total cholesterol in hypercholesterolemic adults. Nutr Res 27, 380-386.

27. Winham DM, Hutchins AM \& Johnston CS (2007) Pinto bean consumption reduces biomarkers for heart disease risk. $J \mathrm{Am}$ Coll Nutr 26, 243-249. 
28. Pittaway JK, Robertson IK \& Ball MJ (2008) Chickpeas may influence fatty acid and fiber intake in an ad libitum diet, leading to small improvements in serum lipid profile and glycemic control. J Am Diet Assoc 108, 1009-1013.

29. Cobiac L, McArthur R \& Nestel PJ (1990) Can eating baked beans lower plasma cholesterol? Eur J Clin Nutr 44, 819-822.

30. Duane WC (1997) Effects of legume consumption on serum cholesterol, biliary lipids, and sterol metabolism in humans. J Lipid Res 38, 1120-1128.

31. Pittaway JK, Ahuja KD, Cehun M, et al. (2006) Dietary supplementation with chickpeas for at least 5 weeks results in small but significant reductions in serum total and lowdensity lipoprotein cholesterols in adult women and men. Ann Nutr Metab 50, 512-518.

32. Pittaway JK, Ahuja KD, Robertson IK, et al. (2007) Effects of a controlled diet supplemented with chickpeas on serum lipids, glucose tolerance, satiety and bowel function. $J \mathrm{Am}$ Coll Nutr 26, 334-340.

33. Anderson JW, Gustafson NJ, Spencer DB, et al. (1990) Serum lipid response of hypercholesterolemic men to single and divided doses of canned beans. Am J Clin Nutr 51, 1013-1019.

34. Finley JW, Burrell JB \& Reeves PG (2007) Pinto bean consumption changes SCFA profiles in fecal fermentations, bacterial populations of the lower bowel, and lipid profiles in blood of humans. J Nutr 137, 2391-2398.

35. Mackay S \& Ball MJ (1992) Do beans and oat bran add to the effectiveness of a low-fat diet? Eur J Clin Nutr 46, 641-648.

36. Marques RG, Fontaine MJ \& Rogers J (2004) C-peptide: much more than a byproduct of insulin biosynthesis. Pancreas 29, 231-238.

37. Wilhelm B, Kann P \& Pfützner A (2008) Influence of C-peptide on glucose utilisation. Exp Diabetes Res 2008, 769483.

38. Papanikolaou Y \& Fulgoni VL III (2008) Bean consumption is associated with greater nutrient intake, reduced systolic blood pressure, lower body weight, and a smaller waist circumference in adults: results from the National Health and
Nutrition Examination Survey 1999-2002. J Am Coll Nutr 27, 569-576.

39. Dalton M, Cameron AJ, Zimmet PZ, et al. (2003) Waist circumference, waist-hip ratio and body mass index and their correlation with cardiovascular disease risk factors in Australian adults. J Intern Med 254, 555-563.

40. Stanley S, Wynne K, McGowan B, et al. (2005) Hormonal regulation of food intake. Physiol Rev 85, 1131-1158.

41. MacDonald PE, El-Kholy W, Riedel MJ, et al. (2002) The multiple actions of GLP-1 on the process of glucosestimulated insulin secretion. Diabetes 51, Suppl. 3, S434-S442.

42. Kadowaki T, Yamauchi T, Kubota N, et al. (2006) Adiponectin and adiponectin receptors in insulin resistance, diabetes, and the metabolic syndrome. J Clin Invest 116, 1784-1792.

43. Weigle DS, Duell PB, Connor WE, et al. (1997) Effect of fasting, refeeding, and dietary fat restriction on plasma leptin levels. J Clin Endocrinol Metab 82, 561-565.

44. Keim NL, Stern JS \& Havel PJ (1998) Relation between circulating leptin concentrations and appetite during a prolonged, moderate energy deficit in women. Am J Clin Nutr 68, 794-801.

45. Wisse BE, Campfield LA, Marliss EB, et al. (1999) Effect of prolonged moderate and severe energy restriction and refeeding on plasma leptin concentrations in obese women. Am J Clin Nutr 70, 321-330.

46. van Rossum EF, Nicklas BJ, Dennis KE, et al. (2000) Leptin responses to weight loss in postmenopausal women: relationship to sex-hormone binding globulin and visceral obesity. Obes Res 8, 29-35.

47. Weigle DS, Cummings DE, Newby PD, et al. (2003) Roles of leptin and ghrelin in the loss of body weight caused by a low fat, high carbohydrate diet. J Clin Endocrinol Metab 88, 1577-1586.

48. Belobrajdic DP, Frystyk J, Jeyaratnaganthan N, et al. (2010) Moderate energy restriction-induced weight loss affects circulating IGF levels independent of dietary composition. Eur J Endocrinol 162, 1075-1082. 